Supporting information

\title{
Nanosized Lithium-rich Cobalt Oxide Particles and their Transformation to Lithium Cobalt Oxide Cathodes with Optimized High-rate Morphology
}

Peter M. Zehetmaier, Arnaud Cornélis, Florian Zoller, Bernhard Böller, Andreas Wisnet, Markus Döblinger, Daniel Böhm, Thomas Bein, Dina Fattakhova-Rohlfing*

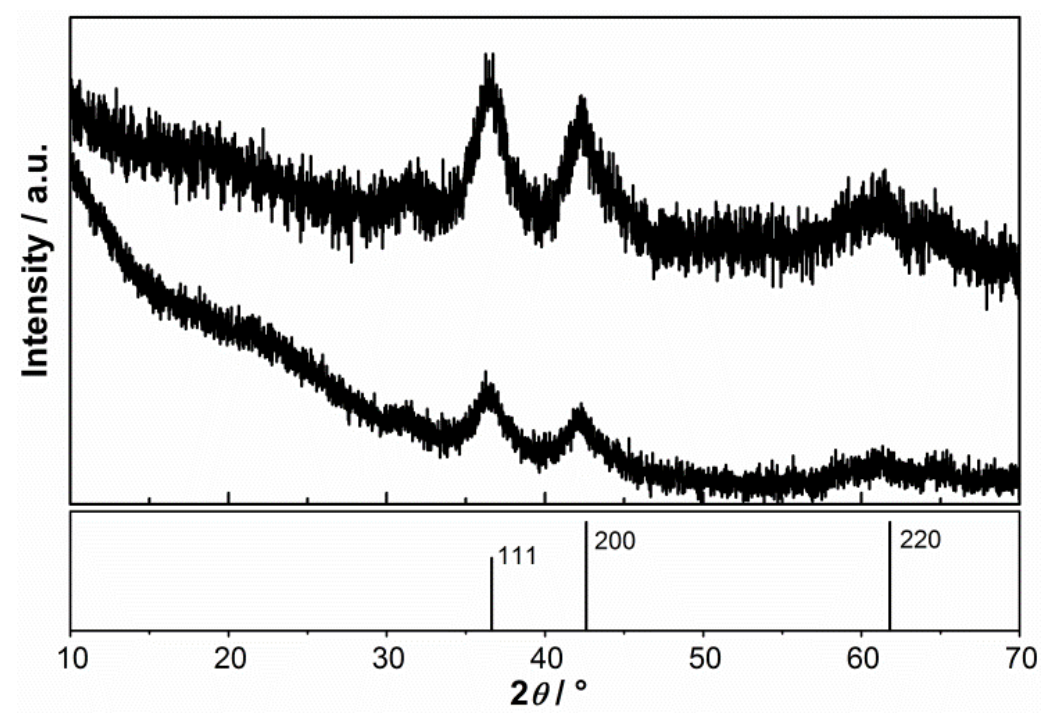

Figure S1 XRD patterns of as-prepared (bottom) and washed (top) $\mathrm{Li}_{x} \mathrm{Co}_{1-x} \mathrm{O}_{y}$ nanoparticles.

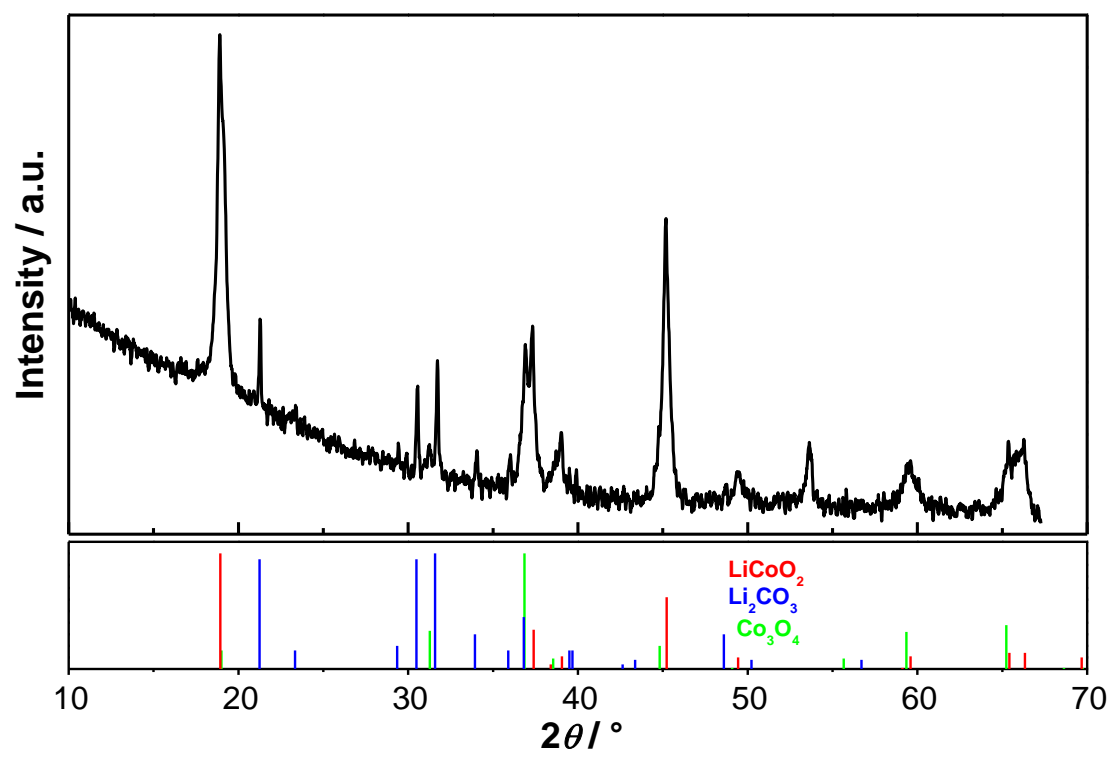

Figure S2 XRD pattern of the product of solvothermal reaction using $\mathrm{LiOH}$ as a lithium source after calcination at $580{ }^{\circ} \mathrm{C}$. In addition to $\mathrm{HT}-\mathrm{LCO}, \mathrm{Li}_{2} \mathrm{CO}_{3}$ and $\mathrm{Co}_{3} \mathrm{O}_{4}$ are formed as side phases. 


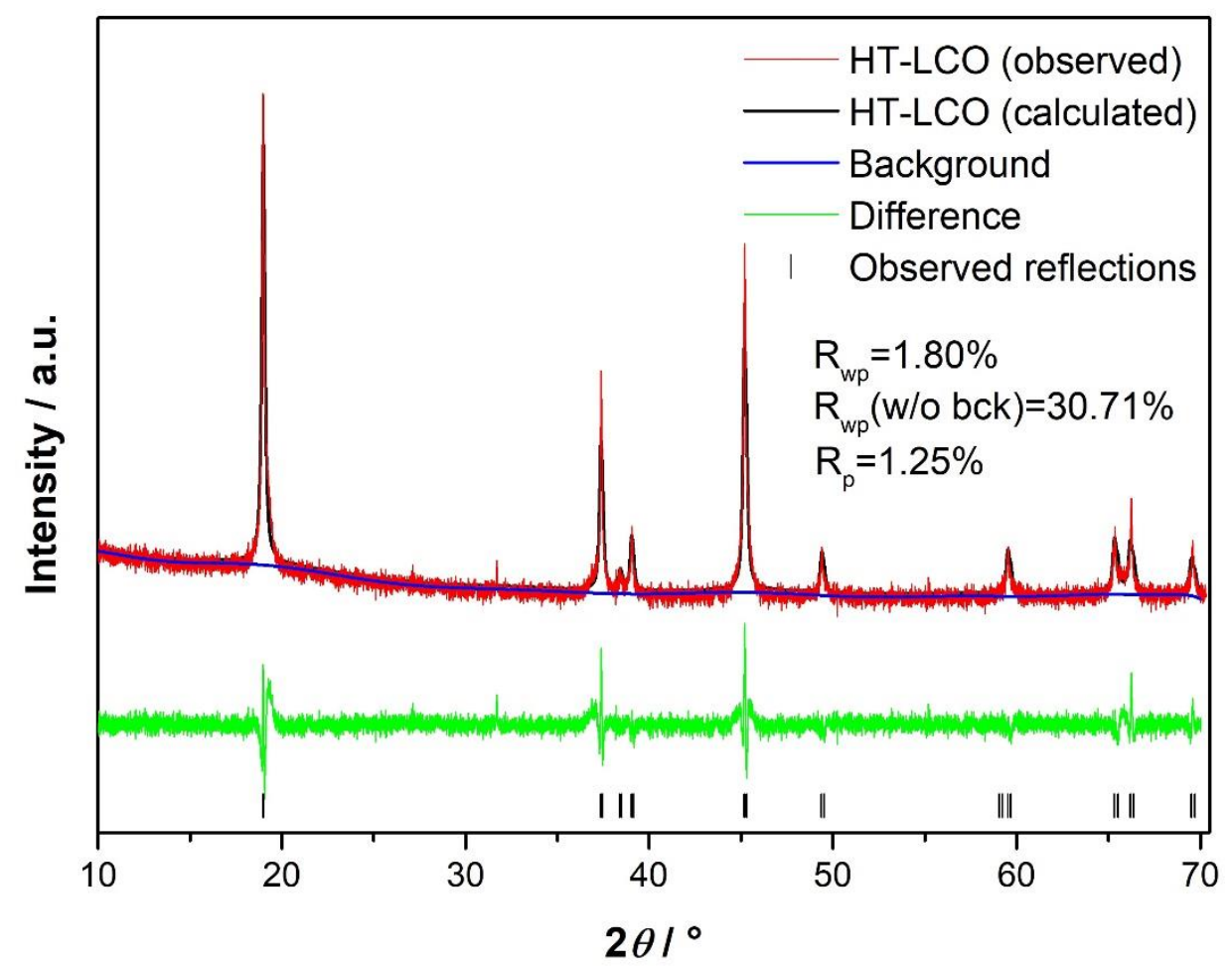

Figure S3 Observed, calculated, background and difference profiles for the Rietveld refinement of HT-LCO.

\section{$\underline{\text { Rietveld refinement of HT-LCO }}$}

The Rietveld refinement of the HT-LCO leads to an Rwp value of $1.80 \%$. All peaks are in good accordance with the calculated reflections of HT-LCO, with exception of the small peak at around $31^{\circ}$ which can be assigned to $\mathrm{Li}_{2} \mathrm{CO}_{3}$. Due to a very small intensity of this peak and the resulting poor signal to noise ratio it was not possible to do Rietveld refinement on this $\mathrm{Li}_{2} \mathrm{CO}_{3}$ side phase 


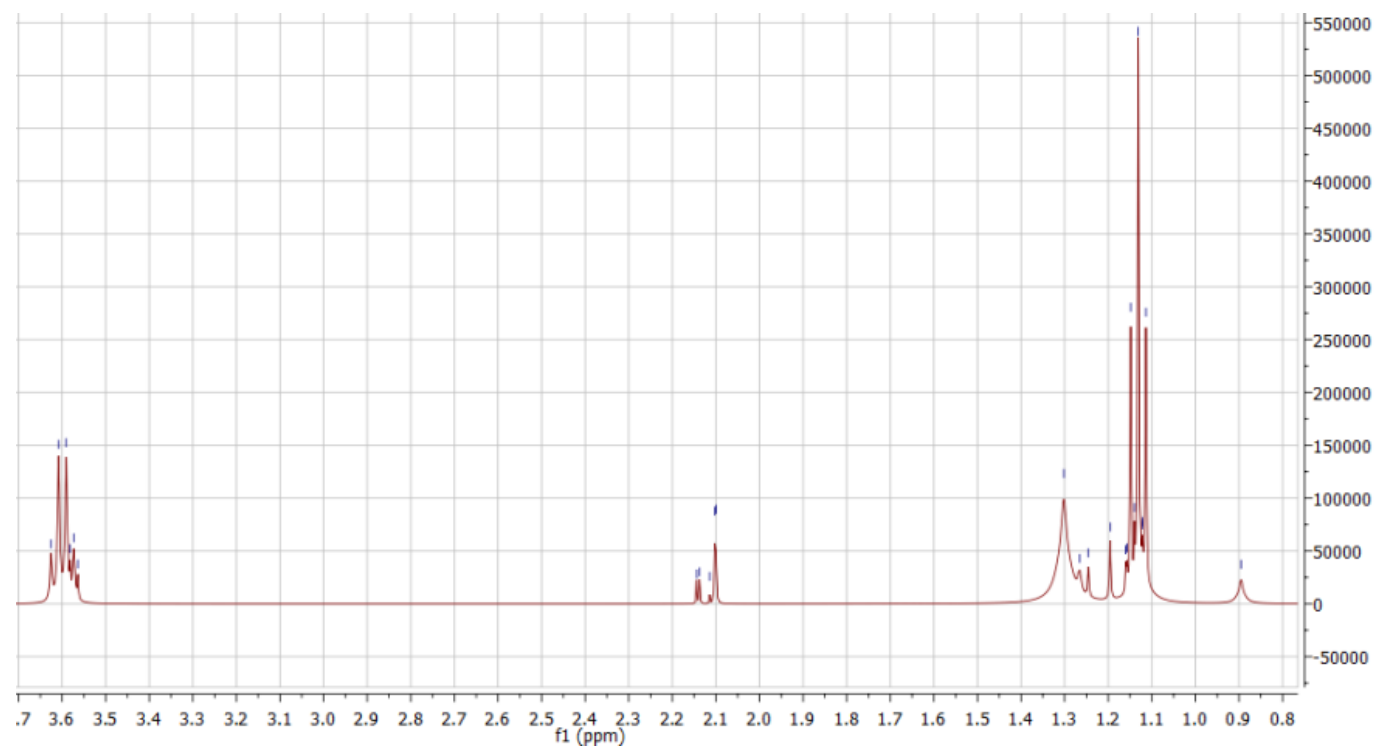

Figure S4 ${ }^{1} \mathrm{H}$ NMR of the dried supernatant obtained after separation of $\mathrm{Li}_{x} \mathrm{Co}_{1-x} \mathrm{O}_{y}$ nanoparticles and dissolved in acetone- $\mathrm{D}_{6}$. The signals correspond to ethanol, acetate and isopropoxide ions, tert-butanol, grease and other unidentified impurities. ${ }^{1}$

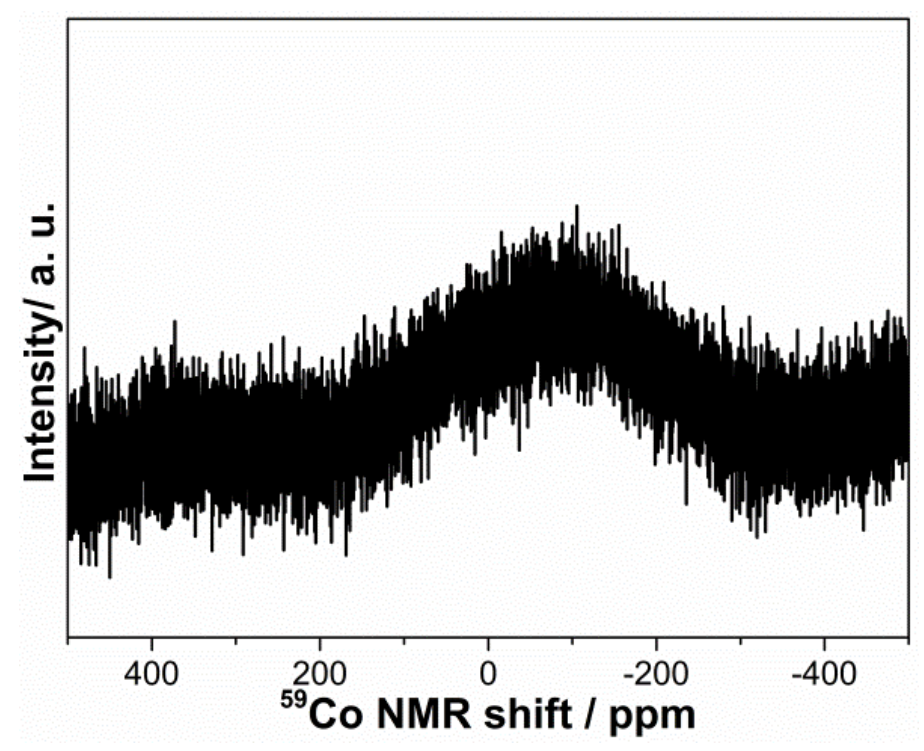

Figure S5 $\quad{ }^{59} \mathrm{Co}$ NMR of the dried supernatant obtained after separation of $\mathrm{Li}_{x} \mathrm{Co}_{1-x} \mathrm{O}_{y}$ nanoparticles and dissolved in acetone- $\mathrm{D}_{6}$. The signal corresponds to the $\mathrm{Co}^{3+}$-ions. 

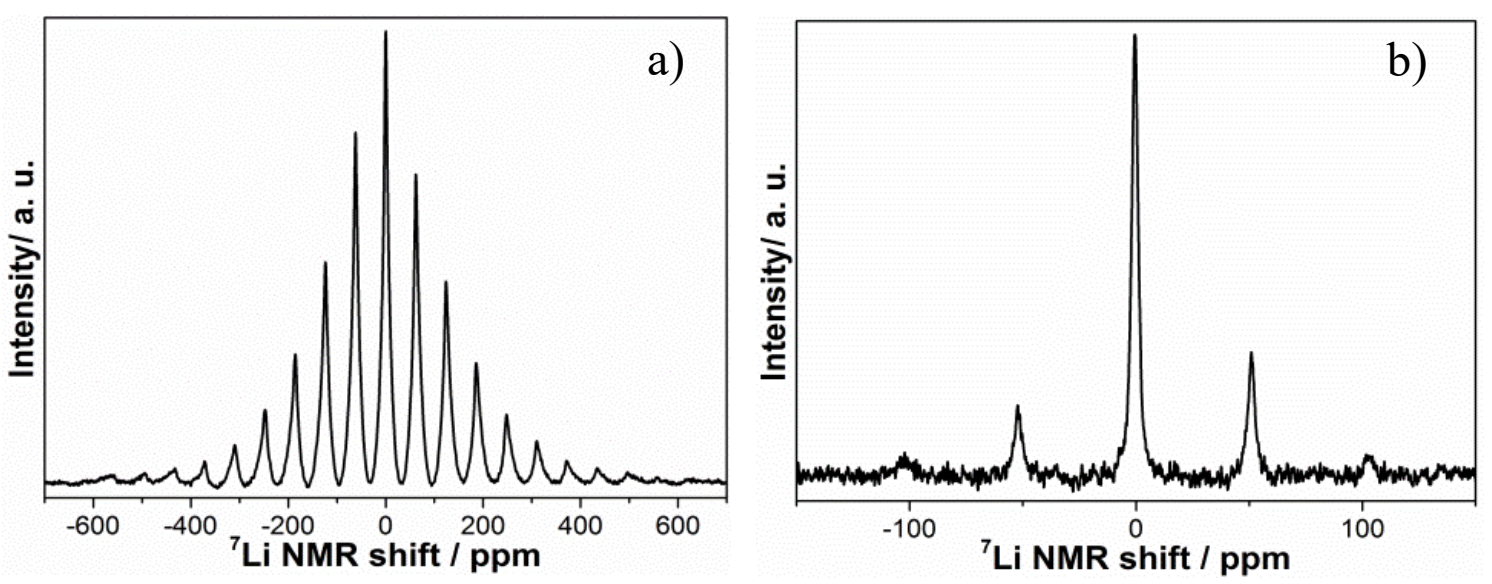

Figure S6 $\quad{ }^{7} \mathrm{Li}$ solid state MAS-NMR of (a) as prepared $\mathrm{Li}_{x} \mathrm{Co}_{1-x} \mathrm{O}_{y}$ nanoparticles and (b) HT-LCO nanoparticles obtained after their calcination at $560{ }^{\circ} \mathrm{C}$.
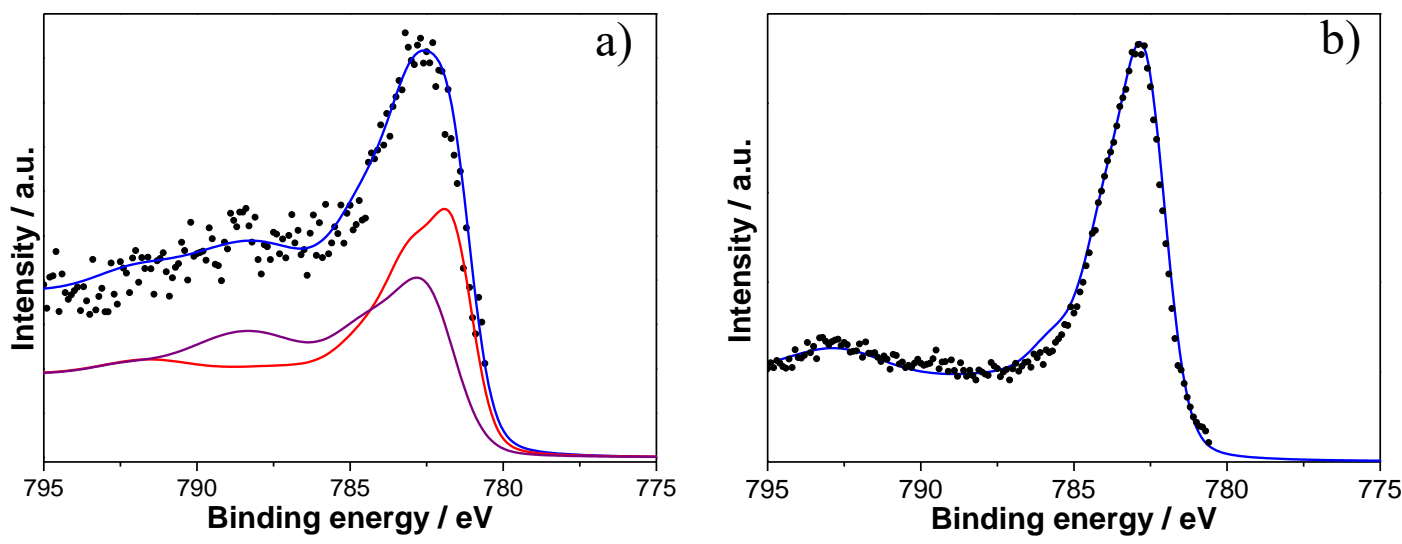

Figure S7 XPS of the Co $2 \mathrm{p}_{3 / 2}$ peak on (a) as prepared $\mathrm{Li}_{x} \mathrm{Co}_{1-x} \mathrm{O}_{y}$ nanoparticles and (b) HT-LCO nanoparticles obtained after their calcination at $560{ }^{\circ} \mathrm{C}$.

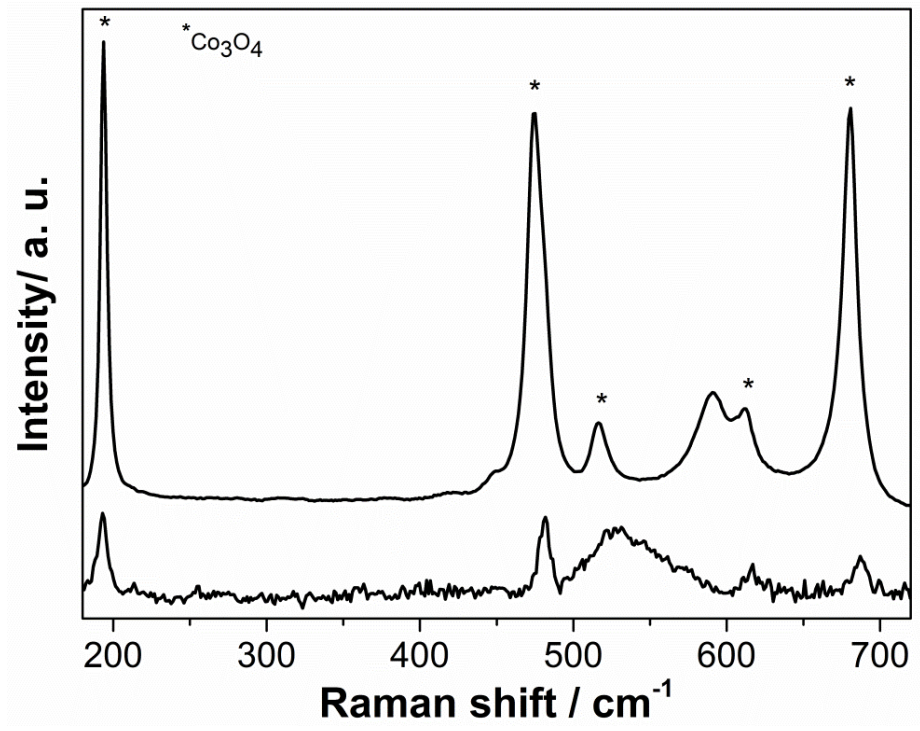

Figure S8 Raman spectra of as-prepared $\mathrm{Li}_{x} \mathrm{Co}_{1-x} \mathrm{O}_{y}$ nanoparticles at $1.7 \mathrm{~mW}$ (lower spectrum) and $8.5 \mathrm{~mW}$ laser power (upper spectrum). Impurities of $\mathrm{Co}_{3} \mathrm{O}_{4}$ are indicated. 


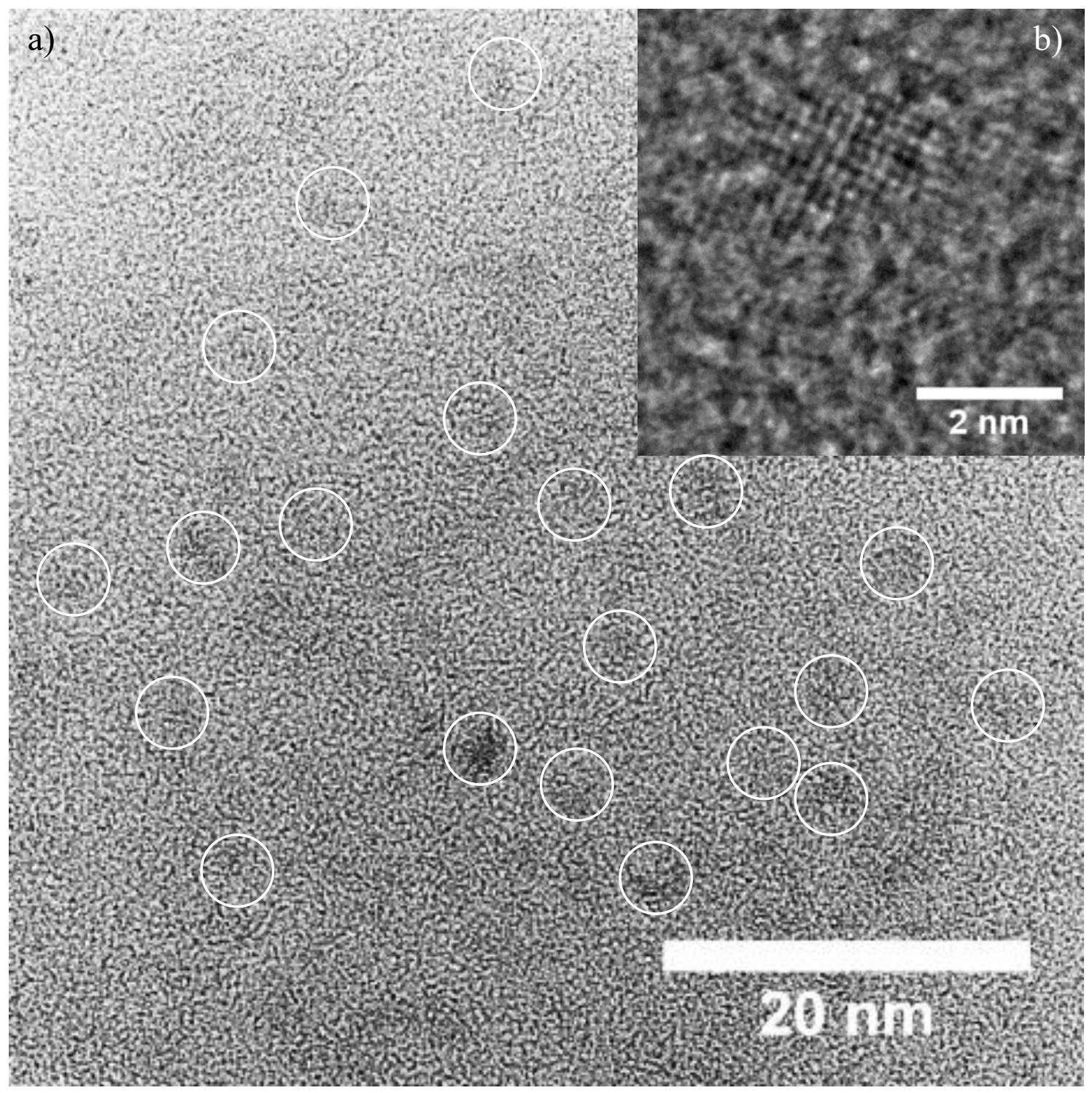

Figure S9 (a) TEM overview image of dispersed and non-agglomerated $\mathrm{Li}_{x} \mathrm{Co}_{1-x} \mathrm{O}_{y}$ nanoparticles after washing (selection of the individual nanoparticles is circled). (b) TEM image of a single $\mathrm{Li}_{x} \mathrm{Co}_{1-x} \mathrm{O}_{y}$ nanoparticle.
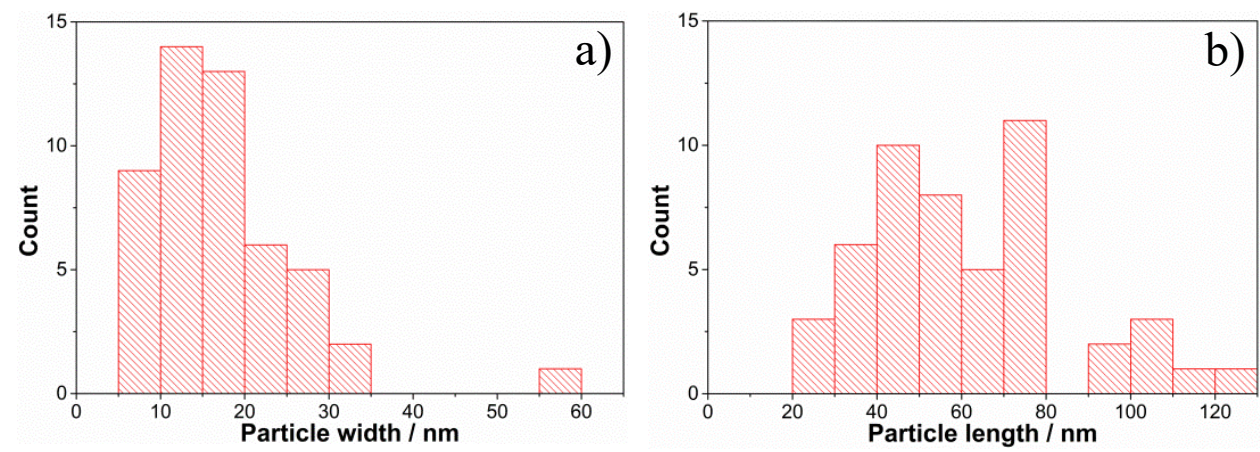

Figure S10 Width (a) and length (b) of the HT-LCO nanoparticles obtained by measurement of 50 particles in HRTEM images. 


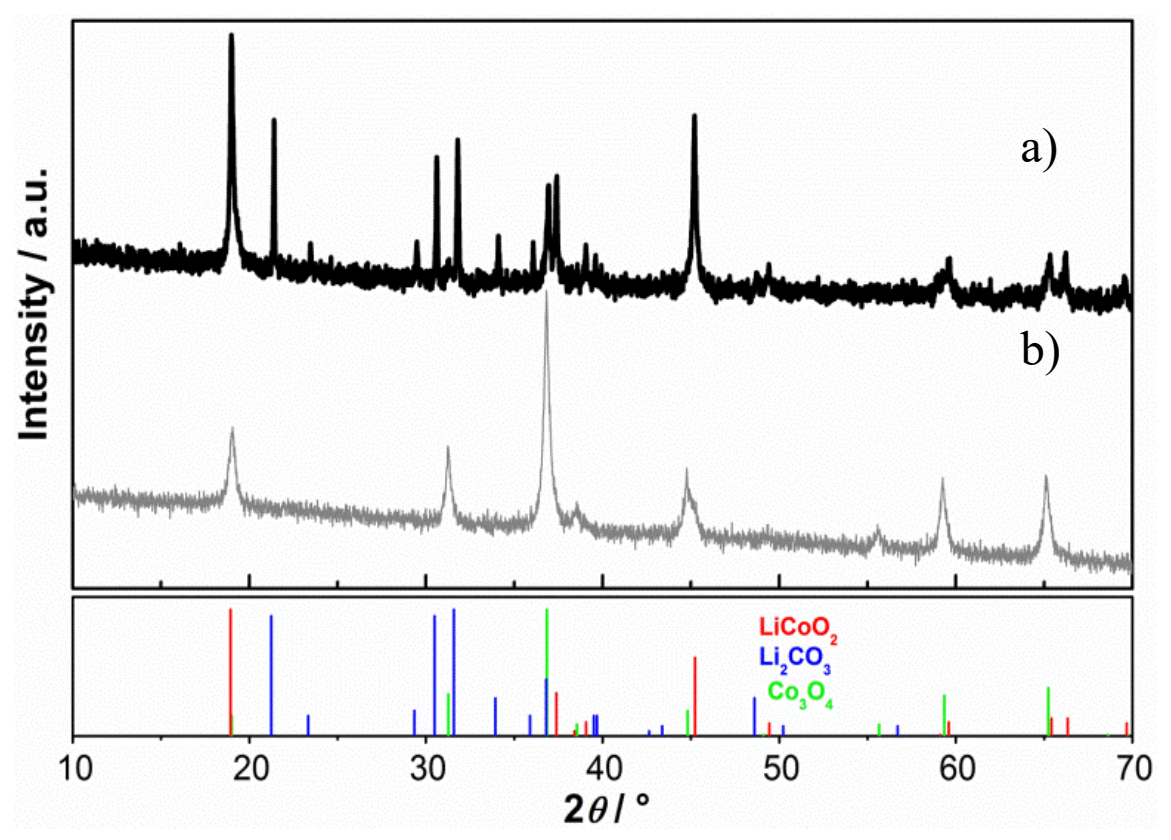

Figure S11 (a) XRD pattern of the reaction product obtained after calcination of washed $\mathrm{Li}_{0.15} \mathrm{Co}_{0.85} \mathrm{O}_{y}$ nanoparticles and added $\mathrm{LiO} i \mathrm{Pr}$ mixed in molar ratio of 1:0.95 at $560{ }^{\circ} \mathrm{C}$. (b) XRD pattern of the reaction product obtained after calcination of washed $\mathrm{Li}_{0.15} \mathrm{Co}_{0.85} \mathrm{O}_{y}$ nanoparticles at $560{ }^{\circ} \mathrm{C}$ without any additional $\mathrm{Li}$ source.

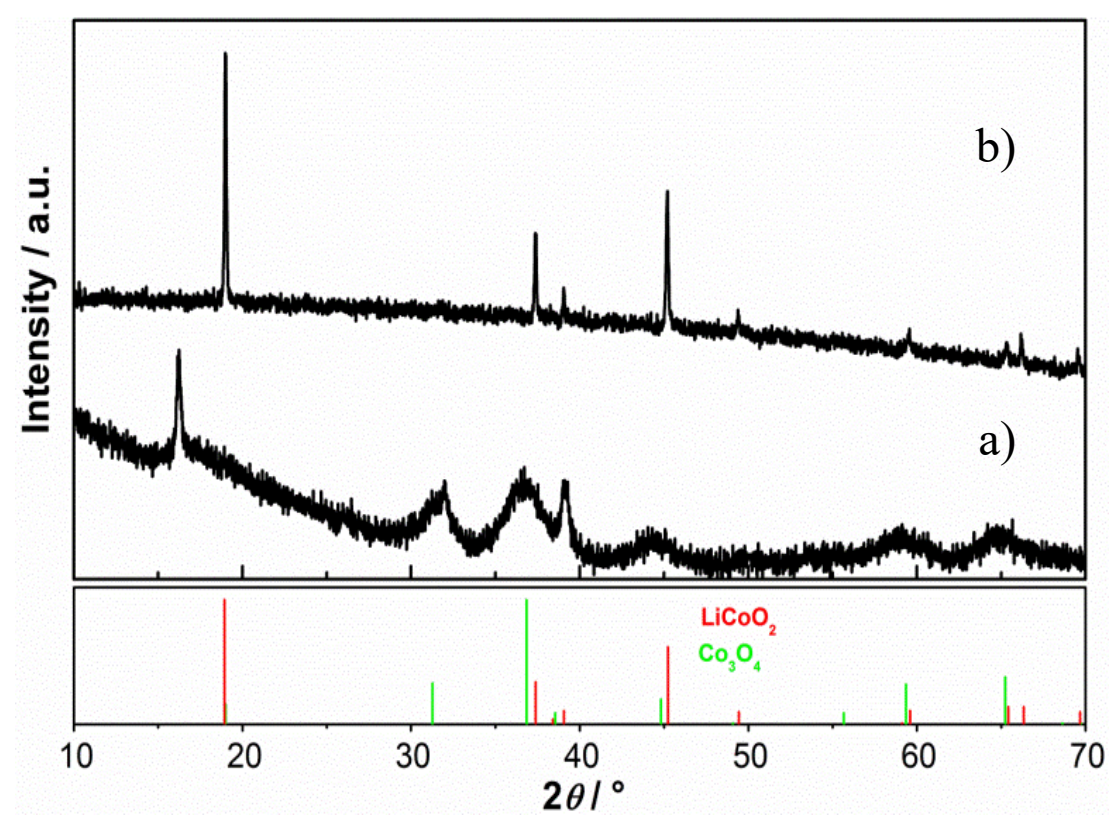

Figure S12 (a) XRD pattern of the product of solvothermal synthesis in tert-butanol performed with only $\mathrm{Co}(\mathrm{OAc})_{2}$ without addition of $\mathrm{LiO} i \mathrm{Pr}$ and $(\mathrm{b})$ the product of its calcination at $560{ }^{\circ} \mathrm{C}$ after mixing with lithium $\mathrm{LiO} i \mathrm{Pr}$ in a molar ratio of 1:1.05. 


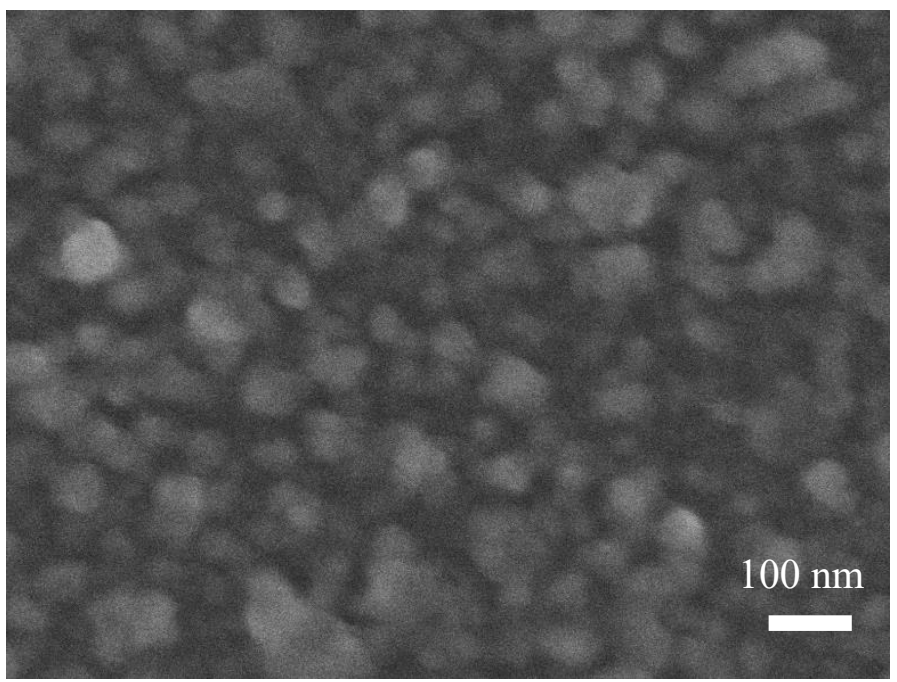

Figure S13 SEM image of the product of solvothermal synthesis in tert-butanol performed with only $\mathrm{Co}(\mathrm{OAc})_{2}$ without addition of $\mathrm{LiO} i \mathrm{Pr}$.

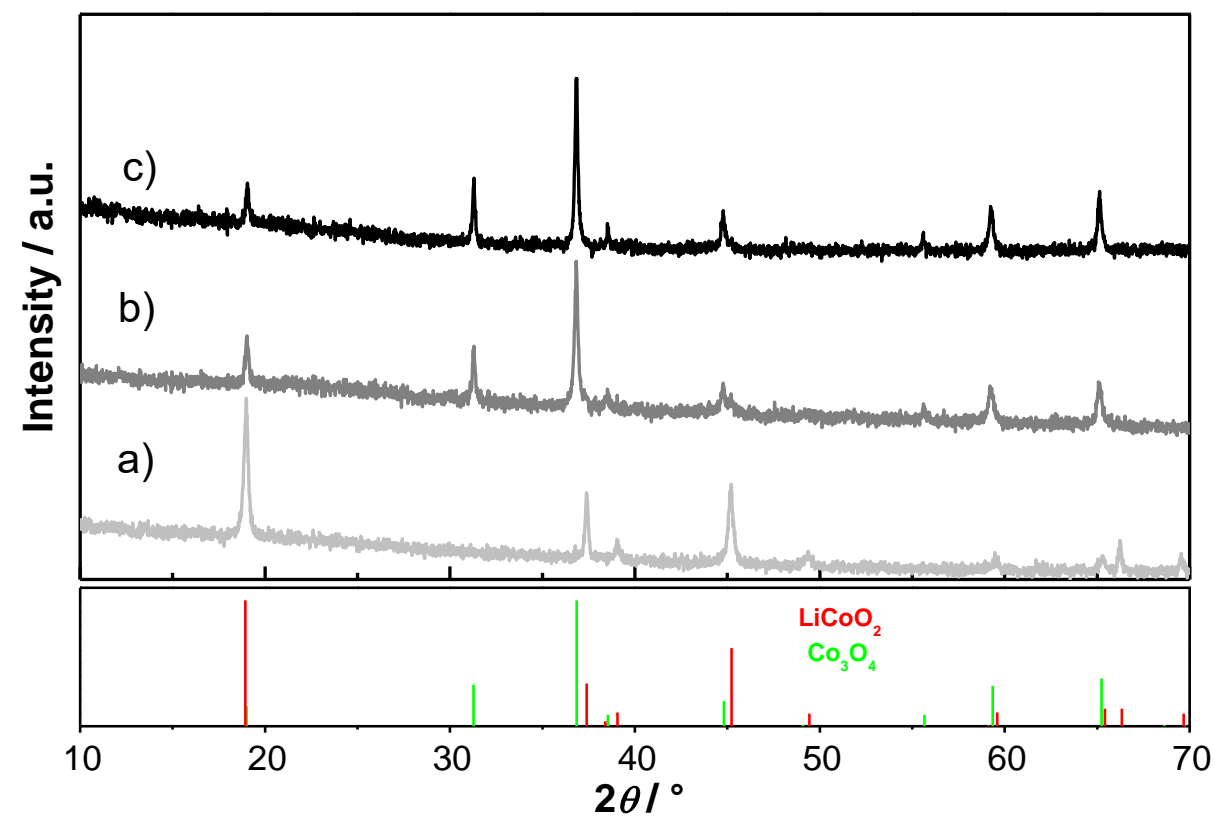

Figure S14 XRD patterns of $\mathrm{Li}_{0.15} \mathrm{Co}_{0.85} \mathrm{O}_{y}$ nanoparticles after calcination at (a) $580{ }^{\circ} \mathrm{C}$, (b) $600{ }^{\circ} \mathrm{C}$ and (c) $625^{\circ} \mathrm{C}$. 

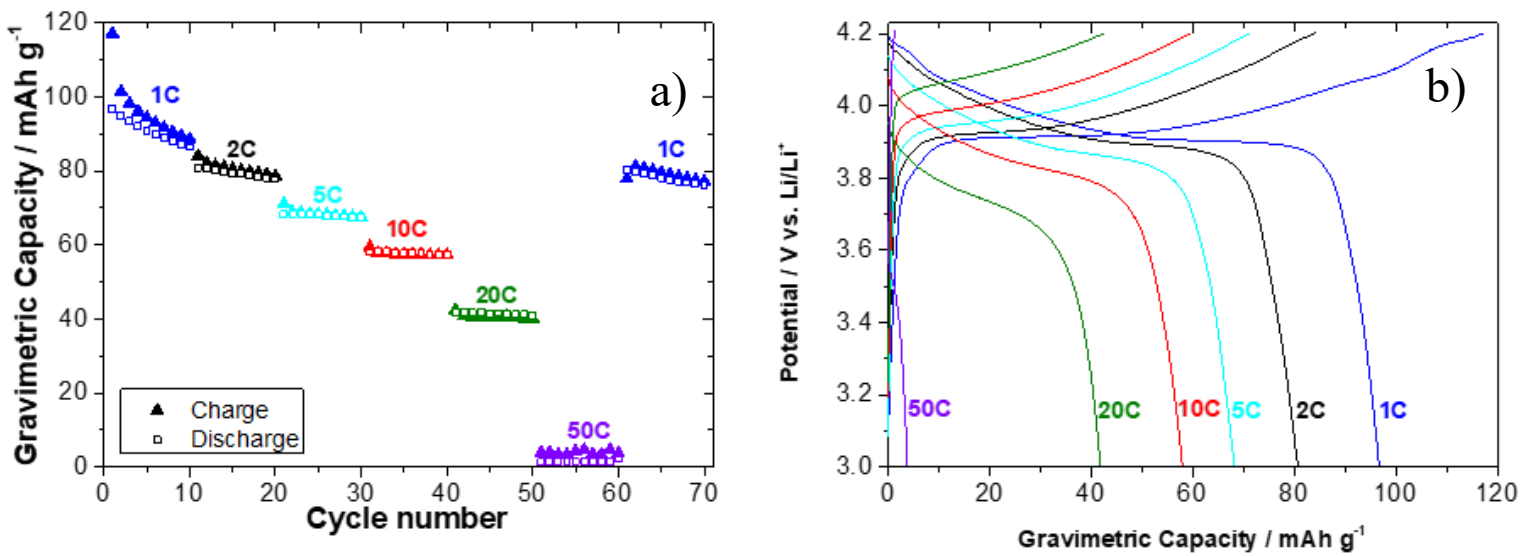

Figure S15 (a) Rate performance measurement at different C-rates (1C-50C) of HT-LCO obtained after calcination at $580{ }^{\circ} \mathrm{C}$, and (b) corresponding galvanostatic charge/discharge (first) curves.

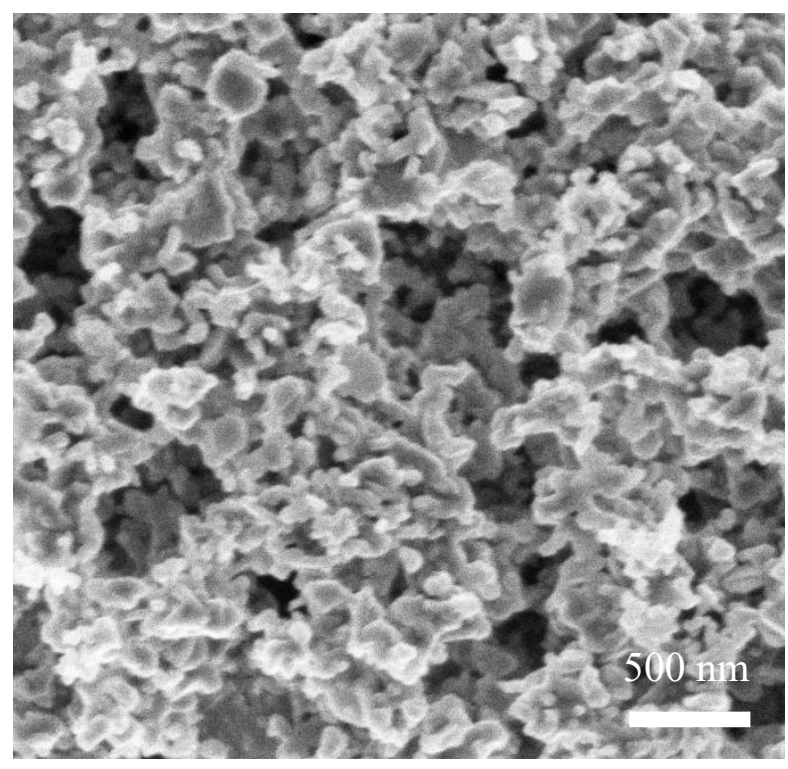

Figure S16 SEM image of HT-LCO obtained after calcination at $580{ }^{\circ} \mathrm{C}$. 

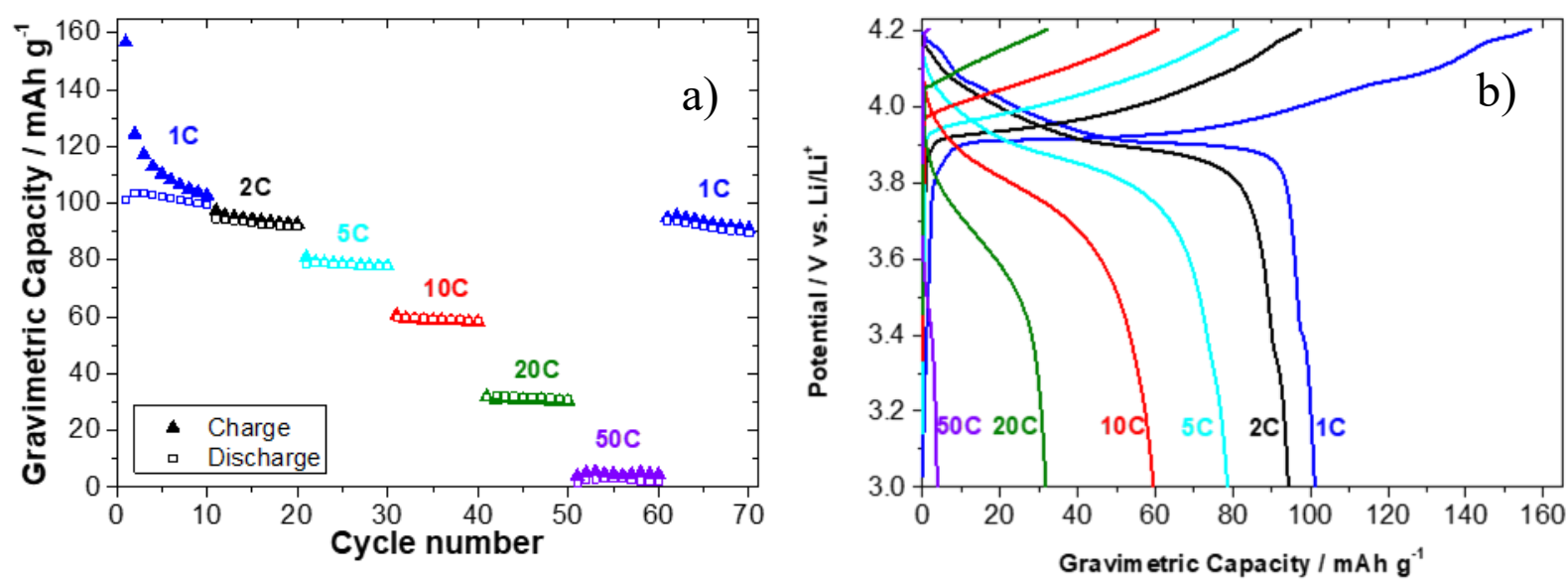

Figure S17 (a) Rate performance measurement at different C-rates (1C-50C) of HT-LCO obtained by the transformation of $\mathrm{Co}_{3} \mathrm{O}_{4}$ and (b) corresponding galvanostatic charge/discharge (first) curves.

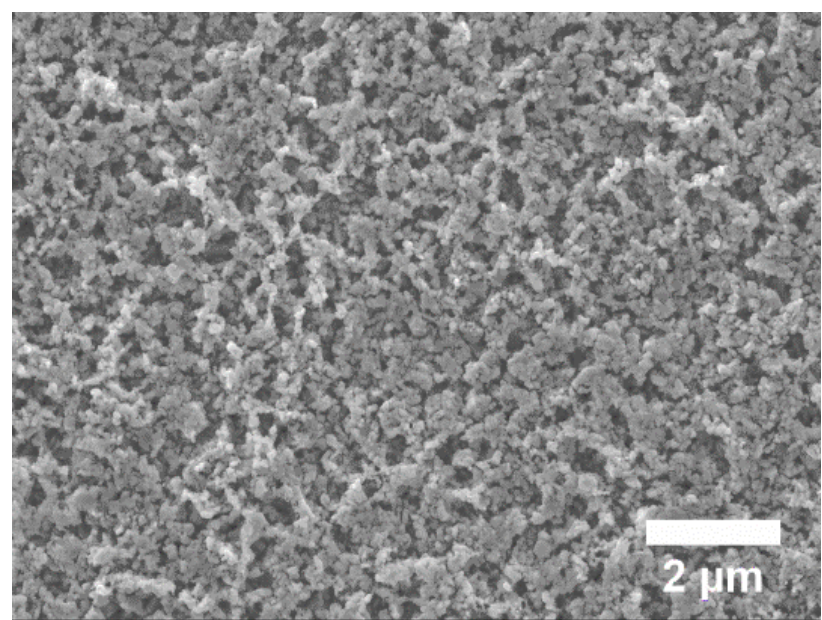

Figure S18 SEM image of a LCO film resulting after calcination of as prepared $\mathrm{Li}_{x} \mathrm{Co}_{1-x} \mathrm{O}_{y}$ nanoparticles with templating agent in low magnification.

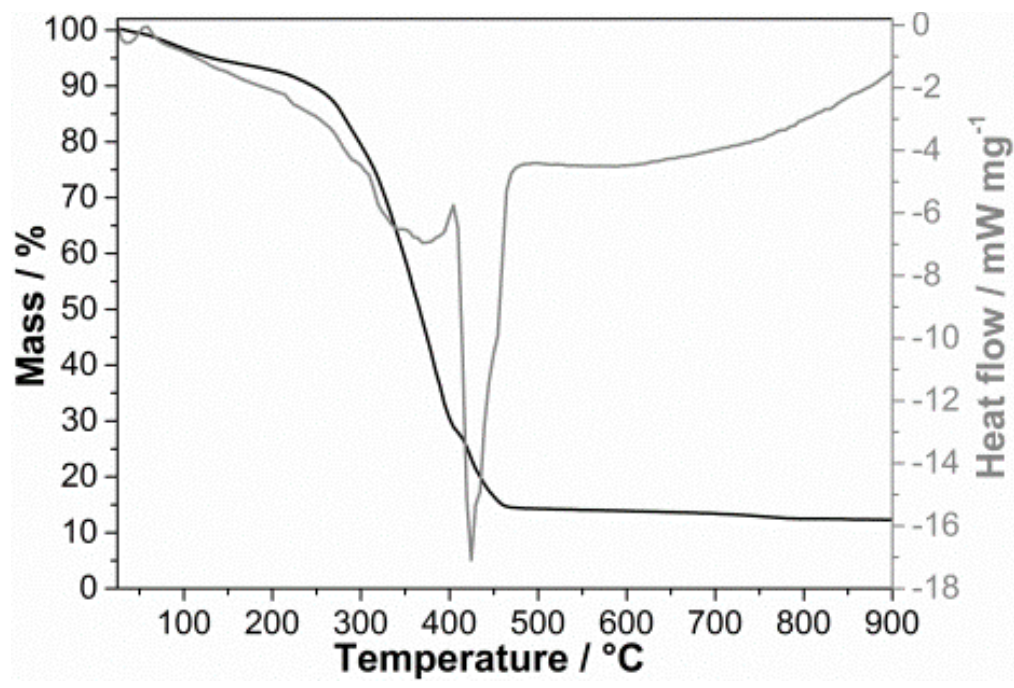

Figure S19 TGA (left axis) and DSC (right axis) of the mixture of as prepared $\mathrm{Li}_{x} \mathrm{Co}_{1-x} \mathrm{O}_{y}$ nanoparticles and Pluronic F127 in air. 

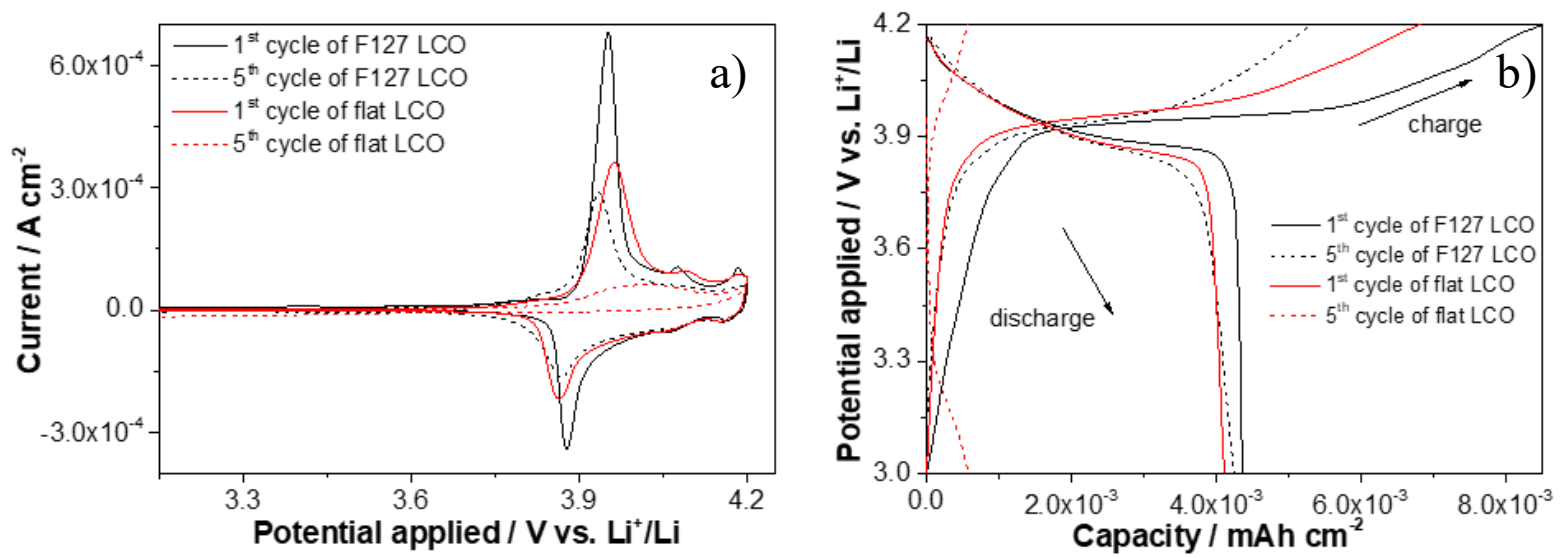

Figure S20 (a) Cyclic voltammograms of flat (red) and Pluronic F127 structured LCO (black) and (b) their integrated capacities.

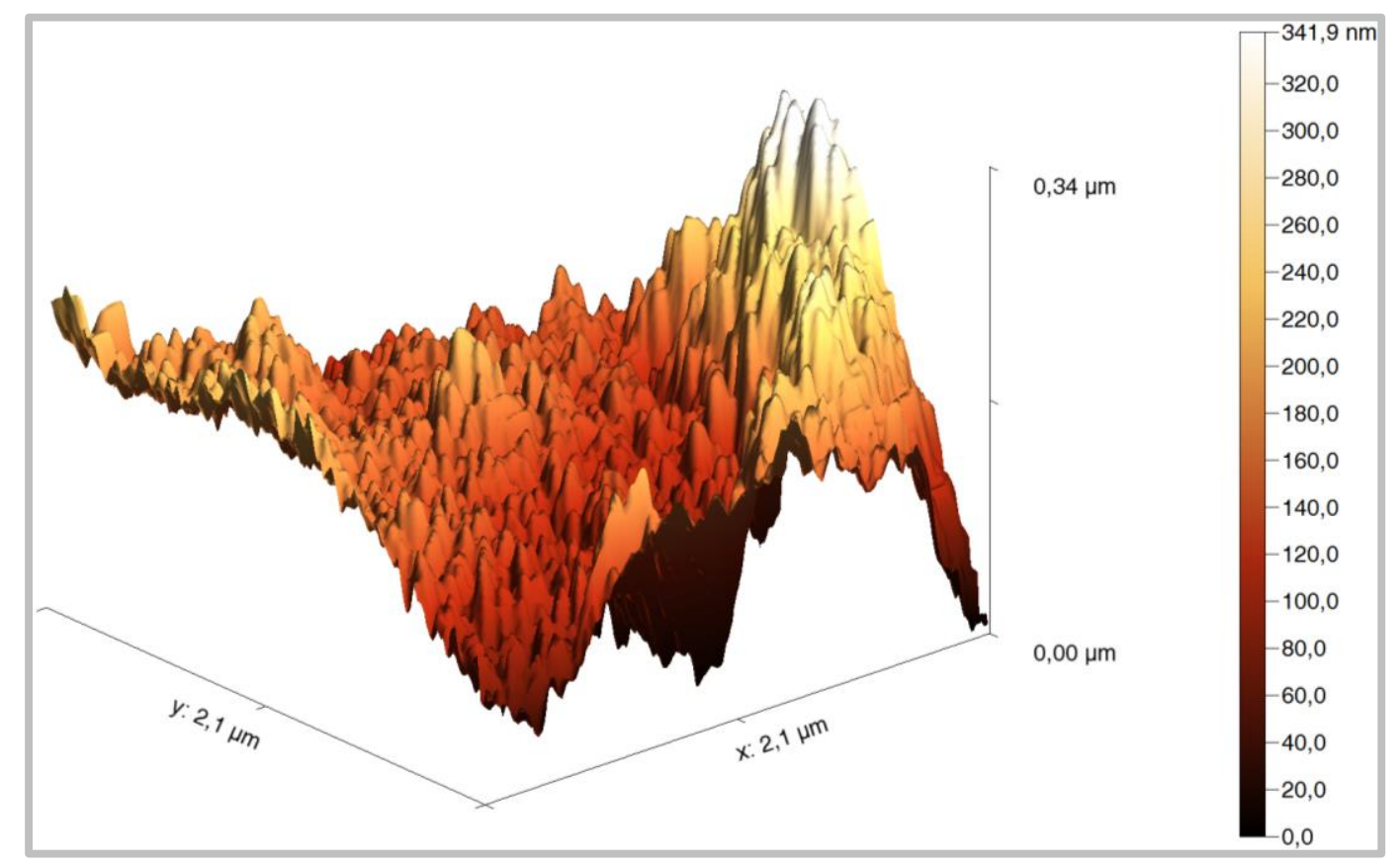

Figure S21 AFM image (three-dimensional plot) of the nanostructured HT-LCO film after calcination. 


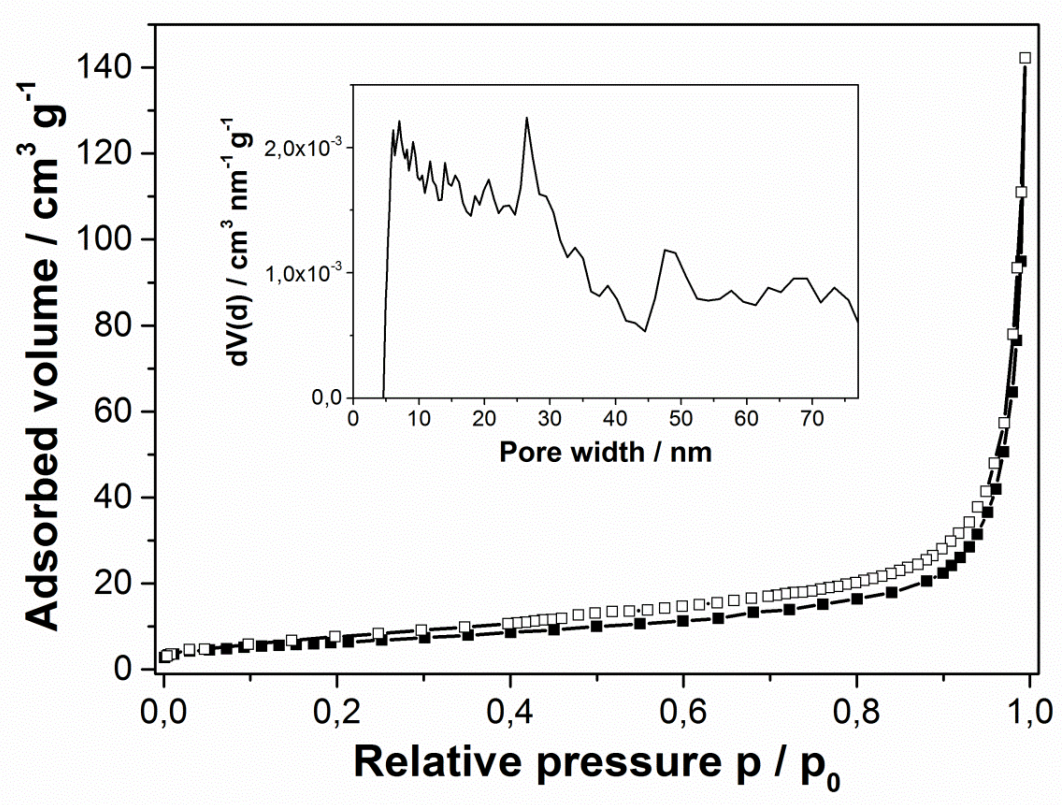

Figure S22 Nitrogen sorption on nanostructured HT-LCO. Pore size distribution obtained with the NLDFT method is shown in an inset.

\section{Comparison of high-rate performance of reported HT-LCO cathodes}

One of the fastest HT-LCO electrodes was prepared by Okubo et al. ${ }^{2}$ from hydrothermallygrown $17 \mathrm{~nm}$ wide nanoparticles. The authors have used, however, a very high content of carbon black (45\%) that drastically enhances the conductivity even at very high current densities. The electrodes by Okubo et al. show a high value of $90 \mathrm{mAh} \mathrm{g}^{-1}$ compared to $72 \mathrm{mAh} \mathrm{g}^{-1}$ for our nanostructured HT-LCO electrode charged at 50C. However, it should be noted that our material yields a higher discharge capacity at $1 \mathrm{C}\left(132 \mathrm{mAh} \mathrm{g}^{-1}\right)$ as compared to $120 \mathrm{mAh} \mathrm{g}^{-1}$ by Okubo et al. Taking the masses of the additional conducting material, mostly carbon black, and the polymeric binder into account, we can re-evaluate and compare the capacity per ink mass. This reduces the values of Okubo et $a l^{2}$ to $60 \mathrm{mAh} \mathrm{gink}^{-1}$ and $45 \mathrm{mAh} \mathrm{g}_{\text {ink }}{ }^{-1}$ at $1 \mathrm{C}$ and 50C, respectively, while our material still yields $106 \mathrm{mAh} \mathrm{gink}^{-1}$ and

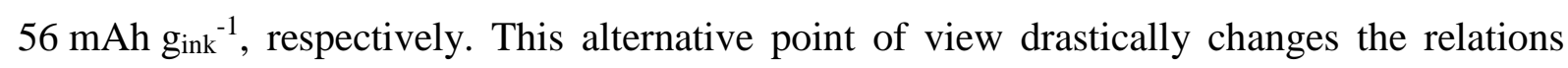
towards our material and is a more realistic approach with respect to commercial use. Additionally, it should be noted that the capacity drops quite strongly between first and second cycle due to the formation of a cathodic surface-electrolyte-interphase. In this study, the discharge capacity at $50 \mathrm{C}$ was determined after the overall $51^{\text {st }}$ cycle and not after the $1^{\text {st }}$ and does not overestimate the discharge capacity by taking non-reversible charges of the cathodic SEI formation into account. Therefore, some groups normalize their data to the values of the fourth cycle to make a more realistic comparison. ${ }^{3}$ 
Another parameter which makes the comparison of the electrodes difficult is the different cut-off potential used for charging. At a cut-off potential of $4.2 \mathrm{~V} \mathrm{vs.} \mathrm{Li} / \mathrm{Li}^{+}$, half of all lithium ions are extracted. Higher cut-off voltages, such as $4.3 \mathrm{~V}, 4.5 \mathrm{~V}$ or even $4.8 \mathrm{~V}$ vs. $\mathrm{Li} / \mathrm{Li}^{+}$, result in a stronger lithium ion extraction from the HT-LCO. Therefore, discharge capacities far beyond $137 \mathrm{mAh} \mathrm{g}^{-1}$ can be reached and theoretical capacity limits can be derived from the literature (see Table S1). ${ }^{4}$ Hence, in order to compare the performance of materials at different $\mathrm{C}$ rates properly the theoretical capacity for the material at each cut-off voltage should be taken into account. By this approach, the mobility of the lithium ions within the different materials expressed as the respectively achieved capacities can be compared in a more direct way as at least the time parameter is fixed.

Table S1 Minimal expected theoretical capacities of HT-LCO for different cut-off voltages. $^{4}$

\begin{tabular}{|c|c|c|c|c|c|}
\hline Cut-off voltage / V vs. $\mathrm{Li}^{-\mathrm{Li}^{+}}$ & 4.2 & 4.3 & 4.4 & 4.5 & 4.8 \\
\hline Minimal theoretical capacity / $\mathrm{mAh} \mathrm{g}^{-1}$ & 137 & 156 & 167 & 192 & 241 \\
\hline
\end{tabular}

Wu et $a .^{5}$ showed flake-like HT-LCO by a solid state synthesis and cycled them with an upper cut-off of $4.5 \mathrm{~V}$ vs. $\mathrm{Li} / \mathrm{Li}^{+}$. The maximum discharge capacity they obtained was $179 \mathrm{mAh} \mathrm{g}^{-1}$ for the first cycle at $0.1 \mathrm{C}\left(14 \mathrm{~mA} \mathrm{~g}^{-1}\right)$. This is around $93 \%$ of the possible achievable capacity. Each individual C-rate cycling step was repeated five times which returned $166 \mathrm{mAh} \mathrm{g}^{-1}$ for $1 \mathrm{C}$ which is significantly higher than reported in this work. Taking into account the $300 \mathrm{mV}$ higher cut-off voltage, the actual C-rate reduces to $0.7 \mathrm{C}$ and hence, only $86 \%$ of the theoretical capacity are reached. In this work over $92 \%$ of the theoretical capacity is retained at a cut-off potential of $4.2 \mathrm{~V} \mathrm{vs.} \mathrm{Li} / \mathrm{Li}^{+}$in all ten cycles at $1 \mathrm{C}$. Further correction of the values at higher C-rates of $\mathrm{Wu}$ et al. returned $159 \mathrm{mAh} \mathrm{g}^{-1}$ and $116 \mathrm{mAh} \mathrm{g}^{-1}$ for $1.5 \mathrm{C}$ and $3.6 \mathrm{C}$, respectively, where $118 \mathrm{mAh} \mathrm{g}^{-1}$ and $107 \mathrm{mAh} \mathrm{g}^{-1}$ for the higher C-rates $2 \mathrm{C}$ and 5C, respectively, are reported in this work. Another possibility of comparing stated literature values with this work is the collation of the relative capacity retention at different $\mathrm{C}$-rates. Measurement values of $\mathrm{Wu}$ et al. show a $82 \%$ capacity retention which is opposed by $86 \%$ retention at $1.5 \mathrm{C} / 2 \mathrm{C}$ as well as $3.6 \mathrm{C} / 5 \mathrm{C}$ shown by the material introduced in this work. Furthermore, our material was able to deliver a superior absolute capacity of $99 \mathrm{mAh} \mathrm{g}^{-1}$ in comparison to $96 \mathrm{mAh} \mathrm{g}^{-1}$ reported for the HT-LCO flakes of Wu et 
al. Absolute capacities stated were thereby extracted from the overall $31^{\text {st }}$ discharge cycle at C-rates of $10 \mathrm{C}$ with regard to this work and $7.3 \mathrm{C}$ for the value reported by $\mathrm{Wu}$ et al.

Qi and Koenig reported sub-microsized HT-LCO particles cycled up to $4.5 \mathrm{~V}$ with a proportionally higher current density. ${ }^{6}$ By this, the actual C-rates get nearly the same and the results are comparable. Nevertheless, our material showed a better high-rate capability with discharge capacities of $107 \mathrm{mAh} \mathrm{g}^{-1}$ and $99 \mathrm{mAh} \mathrm{g}^{-1}$ at $5 \mathrm{C}$ and $10 \mathrm{C}$, respectively, compared to $94 \mathrm{mAh} \mathrm{g}^{-1}$ and $70 \mathrm{mAh} \mathrm{g}^{-1}$ achieved by Qi and Koenig for the respective C-rates. ${ }^{6}$ Reddy et $a l^{7}$ used procedures similar to ours for their sol-gel derived cherry-blossom-leaf templated HT-LCO, but measured only a capacity of $69 \mathrm{mAh} \mathrm{g}^{-1}$ at $2 \mathrm{C}$ compared to $118 \mathrm{mAh} \mathrm{g}^{-1}$ obtained for nanosizedHT-LCO introduced in this work.

Comparing our material with a desert-rose-type HT-LCO of Chen and Grey, HT-LCO presented in this work exhibits a capacity retention of $95 \%$ up to the $14^{\text {th }}$ cycle at $10 \mathrm{C}$ versus a literature reported $75 \%$ retention obtained for a corrected rate of only $5 \mathrm{C}\left(1000 \mathrm{~mA} \mathrm{~g}^{-1}\right)$ resulting from an increased potential window of up to $4.5 \mathrm{~V} .{ }^{8}$

Brog et al. synthesized cobalt complexes with different lithium precursors which were then converted into nanosized LCO. ${ }^{9}$ Using lithium iso-propoxide (LiOiPr) as precursor resulted in the most promising rate performance at $0.5 \mathrm{C}-2 \mathrm{C}$ (potential window: $2.6-4.4 \mathrm{~V}$ ). At $1 \mathrm{C}$ and $2 \mathrm{C}$ a specific capacity of $\sim 95$ and $\sim 65 \mathrm{mAh} \mathrm{g}^{-1}$ were reached, respectivley. ${ }^{9}$ Our nanosized HT-LCO was also prepared from LiOiPr exhibited at the same C-rates 132 and $118 \mathrm{mAh} \mathrm{g}^{-1}$ within a potential window of $3.0-4.2 \mathrm{~V}$.

Okubo et al. showed for bulk and nanoparticles discharge capacity retention of $93 \%$ and $70 \%$, respectively, after 20 cycles at 10C. HT-LCO introduced in this work thereby maintained 93\% of the initial discharge capacity under comparable conditions. ${ }^{2}$ This shows that the cycling stability of our nanosized HT-LCO material is comparable to that of bulk material.

Hydrothermally prepared nanoparticles by Jo et al. show a discharge retention of $90 \%$ after 30 cycles at a corrected C-rate of $5 \mathrm{C}\left(1000 \mathrm{~mA} \mathrm{~g}^{-1}\right)$ which is just below the discharge retention of $91 \%$ at $10 \mathrm{C}$ reported in this work. ${ }^{10}$ With ongoing cycling at high current density, the advantage of our nanosized HT-LCO material gets more and more pronounced.

Liang et al. report a capacity retention of $77 \%$ after 50 cycles at corrected $5 \mathrm{C}$ with their synthesized nanoparticles, while nanoparticles presented in this work preserve $87 \%$ of the initial discharge capacity after 50 cycles at $10 \mathrm{C} .{ }^{11}$ 
Only a few groups report the performance of their HT-LCO after more than 50 cycles at high current densities. For example, Yadav et al. whose microemulsion derived HT-LCO nanostructures already performed well at various lower C-rates showed a decreased performance at the lower constant $\mathrm{C}$-rate of 5C. Their initial discharge capacity of $110 \mathrm{mAh} \mathrm{g}^{-1}$ is reduced to $82 \mathrm{mAh} \mathrm{g}^{-1}$ after 80 cycles leading to a retention of $75 \%$ which is lower than $82 \%$ capacity retention at $10 \mathrm{C}$ obtained after the same number of charge/discharge cycles shown in our work. ${ }^{12}$

1. Fulmer, G. R.; Miller, A. J. M.; Sherden, N. H.; Gottlieb, H. E.; Nudelman, A.; Stoltz, B. M.; Bercaw, J. E.; Goldberg, K. I., NMR Chemical Shifts of Trace Impurities: Common Laboratory Solvents, Organics, and Gases in Deuterated Solvents Relevant to the Organometallic Chemist. Organometallics 2010, 29 (9), 2176-2179.

2. Okubo, M.; Hosono, E.; Kim, J.; Enomoto, M.; Kojima, N.; Kudo, T.; Zhou, H.; Honma, I., Nanosize Effect on High-Rate Li-Ion Intercalation in $\mathrm{LiCoO}_{2}$ Electrode. J. Amer. Chem. Soc. 2007, 129, 7444-7452.

3. Scott, I. D.; Jung, Y. S.; Cavanagh, A. S.; Yan, Y.; Dillon, A. C.; George, S. M.; Lee, S.-H., Ultrathin Coatings on Nano-LiCoO 2 for Li-Ion Vehicular Applications. Nano Lett. 2011, 11 (2), 414-418.

4. Yabuuchi, N.; Kawamoto, Y.; Hara, R.; Ishigaki, T.; Hoshikawa, A.; Yonemura, M.; Kamiyama, T.; Komaba, S., A comparative study of $\mathrm{LiCoO}_{2}$ polymorphs: structural and electrochemical characterization of O2-, O3-, and O4-type phases. Inorg. Chem. 2013, 52 (15), 9131-42.

5. Wu, N.; Zhang, Y.; Guo, Y.; Liu, S.; Liu, H.; Wu, H., Flakelike $\mathrm{LiCoO}_{2}$ with Exposed $\{010\}$ Facets As a Stable Cathode Material for Highly Reversible Lithium Storage. ACS Appl. Mater. Interfaces 2016, 8 (4), 2723-2731.

6. Qi, Z.; Koenig, G. M., High-Performance $\mathrm{LiCoO}_{2}$ Sub-Micrometer Materials from Scalable Microparticle Template Processing. ChemistrySelect 2016, 1 (13), 3992-3999.

7. Reddy, M. J. K.; Ryu, S. H.; Shanmugharaj, A. M., Synthesis of nanostructured lithium cobalt oxide using cherry blossom leaf templates and its electrochemical performances. Electrochim. Acta 2016, 189 (Supplement C), 237-244.

8. Chen, H.; Grey, C. P., Molten Salt Synthesis and High Rate Performance of the "Desert-Rose" form of $\mathrm{LiCoO}_{2}$. Adv. Mater. 2008, 20 (11), 2206-2210.

9. Brog, J.-P.; Crochet, A.; Seydoux, J.; Clift, M. J. D.; Baichette, B.; Maharajan, S.; Barosova, H.; Brodard, P.; Spodaryk, M.; Züttel, A.; Rothen-Rutishauser, B.; Kwon, N. H.; Fromm, K. M., Characteristics and properties of nano- $\mathrm{LiCoO}_{2}$ synthesized by pre-organized single source precursors: Li-ion diffusivity, electrochemistry and biological assessment. J.Nanobiotechnology 2017, 15 (1), 58.

10. Jo, M.; Hong, Y.-S.; Choo, J.; Cho, J., Effect of $\mathrm{LiCoO}_{2}$ Cathode Nanoparticle Size on High Rate Performance for Li-Ion Batteries. J. Electrochem. Soc. 2009, 156 (6), A430-A434. 11. Liang, H.; Qiu, X.; Chen, H.; He, Z.; Zhu, W.; Chen, L., Analysis of high rate performance of nanoparticled lithium cobalt oxides prepared in molten $\mathrm{KNO}_{3}$ for rechargeable lithium-ion batteries. Electrochem. Commun. 2004, 6 (8), 789-794. 12. Yadav, G. G.; David, A.; Zhu, H.; Caruthers, J.; Wu, Y., Microemulsion-based synthesis and electrochemical evaluation of different nanostructures of $\mathrm{LiCoO}_{2}$ prepared through sacrificial nanowire templates. Nanoscale 2014, 6 (2), 860-866. 